\title{
Meanings Given to Professional Care: Focus Group Results
}

\author{
Mary Kalfoss*, Jenny Owe Cand Scient \\ Diakonova University College, Oslo, Norway \\ Email: *Mary.Kalfoss@diakonova.no
}

How to cite this paper: Kalfoss, M. and Owe, J. (2017) Meanings Given to Professional Care: Focus Group Results. Open Journal of Nursing, 7, 524-547. https://doi.org/10.4236/ojn.2017.75041

Received: April 24, 2017

Accepted: May 16, 2017

Published: May 19, 2017

Copyright $\odot 2017$ by authors and Scientific Research Publishing Inc.

This work is licensed under the Creative Commons Attribution International License (CC BY 4.0).

http://creativecommons.org/licenses/by/4.0/ (c) (i) Open Access

\begin{abstract}
Background: Many studies have focused on exploring the concept of care from patient and nurse perspectives, but knowledge is limited regarding student perceptions. Objective: To explore the meanings given to the concept of professional care from the perspective of graduate students in nursing and pastoral care. Research design: A qualitative study was employed with the formation of six focus groups. Data were analyzed via a thematic content analysis of the discussions. Participants and research context: Thirty-one students attending a University College in Oslo participated. Findings: Seven main themes and forty-four subthemes were identified. Major themes included reverence and respect for the dignity and value of human life, bonding, sensitive to self and other, communication, competence, willfulness and deep caring. Discussion: Different levels of intentionality, professional comportment and caring consciousness were revealed in the discussions. Findings also lend support to major beliefs and values in Watson's Human Caring Theory. Conclusion: The focus groups generated valuable detail of complex experiences behind student's perceptions, attitudes, beliefs and actions. Focus group methodology can enhance holistic nursing practice by providing opportunities to explore and clarify holistic care values, create opportunities for self-awareness and transformative learning in education, clinical practice, administration and research.
\end{abstract}

\section{Keywords}

Caring, Concept, Focus Groups, Nursing, Pastoral Counseling

\section{Introduction}

Thoughts about care today have coalesced into an ethical theory with the power to evaluate personal relationships, professional conduct, public policy, international relationships and global issues [1]. The concept of care/caring is also the 
essence of many caring disciplines and is not exclusively a phenomenon that belongs to the nursing discipline [2] [3]. However, as evidenced by practice and research, nursing has a long legacy as a caring-healing profession and many claim that caring is an integral part of nursing [4] [5] [6] [7]. Further, caring is also emphasized by nursing researchers [7]-[14].

Because caring is a core value in nursing practice, the capacity to care is a desired attribute in nursing students. Likewise, others have discussed the need for caring to be translated and transmitted in the practices of nursing education [15]. Caring has also been cited by many authors as the core value of nurse educator-student relationship. Nurturing a caring attitude in nursing education and in the educator relationship is especially important as this is the students' first confrontation with the significant values and essence of their profession [16]. Despite caring's fundamental place in professional care, education and practice, researchers and scholars have not reached a common definition to transmit to students. This has resulted in a wide array of various interpretations regarding the meanings of professional care, often leading to confusing and contrasting views amongst students, teachers, health professionals and patients. Because post-modern nursing care has become the focus of economical, technological and political and social restraining forces, the need to provide holistic quality care in the contemporary health care system has become urgent together with the importance of cultivating caring in nursing education [17]. Because a critical task of nursing educators is to promote students' learning about caring, it is imperative to explore student's perspectives about the meanings they give to the concept of professional care.

\subsection{Literature Review}

\section{Focus Group Studies on Perceptions of Care/Caring}

The focus group has gained considerable popularity as a means of gathering qualitative data in nursing research over the past 20 years [18] [19] [20]. Focus groups interviews are carefully planned discussions, designed to obtain perceptions on a defined area of interest [21] and are reported to be one of the most acceptable methods for obtaining research information on subjective perceptions [22]. Most authors agree that the main advantage of the focus group interview is the purposeful use of interaction in order to generate data [23]. Merton identifies 3 major components of focus group research as: 1) a method devoted to data collection; 2) interaction as a source of data; and 3) the active role of the researcher in creating group discussion for data collection. Focus groups are particularly suited to capture everyday knowledge from the terms and language people use to give meaning to their everyday world. Focus group interviews have also been shown to contribute to a body of knowledge that is conceptual and theoretical [24]. Schroeder and Neil [25] argued that focus groups are specifically useful for investigating issues in nursing in relation to caring.

Others have also explored the concept of care/caring from a student perspective using focus groups and participant observation. Dobrowolska and col- 
leagues [26] explored how nursing and medical students understood care in their first practicum, and how their views changed over time. Results showed that both medical and nursing students defined care in the same way with themes consisting of compassion, commitment, competence, confidence, conscience, communication, patience, courage and support. Nursing students viewed their caring to be within both practical and emotional dimensions and this was a core feature of their identity as nurses. Medical students, on the other hand, viewed the practical dimension of care as an additional activity. All the students in the study underlined the importance of having time to care and showed that, for them, "time" in this context was embedded in moral meaning.

Sapountzi-Krepia and colleagues [27] conducted focus groups with Greek nursing students exploring their perceptions regarding the concept of care and found that care was related to "care as an emotional order", "care as a service", "care as bodily and psychological support", "care of an individual or group", and "care as a constant phenomenon". In this study, perceptions of care also included the aspect of love. MacNeil and Evans [28] studied the concept of care in nursing education from the perspective of students. In this study, students were asked to describe moments of caring experienced in the educational setting. Themes identified included connectedness, support, presence, respect and promotion/support of personal growth. Karaoz [29] investigated last year undergraduate students' perception of caring. Students were asked to write incidents in which they observed nursing behavior conducted in caring and uncaring ways, followed by interviews. Professional/helping and relational/technical competencies were the major themes discussed.

Although not based upon focus group methodology, Papastavrou and colleagues [30] in a large survey with surgical patients and their nurses found that both patients and nurses perceived knowledge and skill as being the most important caring behaviors. However, they found differences in the importance of human presencing and respectful deference to others, whereas nurses perceived such behavior as being more important than the patients. In a recent study, Begum and Slavin [31] also explored perceptions of caring in nursing education of Pakistani nursing students by personal interviews and found that caring represented a mothering relationship, helping attitude, limit setting, communication, and a source of empowerment and development.

Lastly, in another study focused on the aspect of learning caring, Ma and colleagues [17] explored baccalaureate nursing student's perspective on learning about caring in Chinese focus groups. Results demonstrated four themes which included learning by positive role models as an ideal way of learning about caring, negative role models as another way of learning, lack of directive substance as a hindrance to learning care, and lack of cultural competence as a barrier to learning about caring. In sum, many of the findings in these studies varied in relation to meanings given to care and caring behaviors.

\subsection{Purpose}

Based on focus group methodology, the aim of this study was to explore the 
meanings given to professional care by Norwegian nursing and pastoral students enrolled in post graduate classes in order to increase the body of knowledge regarding care, based on research evidence.

\subsection{Theoretical Framework}

\section{Transpersonal caring relationship}

The theoretical framework for this study is based on Watson's Human Caring Theory which emphasizes caring as a transpersonal caring relationship. For Watson [32], this transpersonal relationship characterizes a special kind of human care relationship, which depends on the nurse's moral commitment in protecting and enhancing human dignity, as well as the deeper/higher self. The nurse's caring consciousness and connection is regarded as having the potential to heal; since experience, perception and intentional connection are taking place. The relationship describes how the nurse goes beyond an objective assessment, showing concerns toward the person's subjective and deeper meaning regarding their own health care situation. This approach highlights the uniqueness of both the person and the nurse, and also the mutuality between two individuals, which is fundamental in the relationship. As such, the one caring and the one caredfor, both connect in mutual search for the meaning and wholeness, and for the spiritual transcendence of suffering. The term "transpersonal" means to go beyond one's own ego and the here and now, as it allows one to reach deeper spiritual connections in promoting patient comfort and healing [7].

\section{Caring Occasion-Caring Moments}

According to Watson, a caring occasion is the moment (focal point in space and time) when the nurse and another person come together in such a way that an occasion for human caring is created [32] [33]. Both persons and their unique phenomenal fields, have a possibility to come together in a human-to-human transaction. For Watson, a phenomenal field corresponds to the person's frame of reference or the totality of human experience consisting of feelings, bodily sensations, thoughts, spiritual beliefs, goals, expectations, environmental considerations, and meanings of one's perceptions-all of which are based upon one's past life history, one's present moment, and one's imagined future [32] [33]. Watson insists that the nurse also needs to be aware of their own consciousness and authentic presence of being in a caring moment with patients. Moreover, both the one cared-for and the one caring can be influenced by the caring moment through the choices and actions decided within the relationship, thereby, influencing and becoming a part of their own life history. The caring occasion becomes transpersonal when "it allows for the presence of the spirit of both- then the event of the moment expands the limits of openness and has the ability to expand human capabilities" ([32], pp. 116-117).

\section{Caritas Processes}

Developed in 1979, and revised in 1985 and 1988, Watson views "carative factors" as a guide for the core of nursing. She uses the term carative to contrast with the conventional medicine's curative factors. Her carative factors attempt to "honor the human dimensions of nursing's work and the inner life world and 
subjective experiences of the people we serve" ([14], p. 50). In all, the carative factors are comprised of 10 elements and is presented in Table 1 ([33], p.75). As she continued to evolve her theory, Watson introduced the concept of clinical caritas processes, which have now replaced her carative factors, containing a greater spiritual dimension in these processes. The word "caritas" originated from the Greek vocabulary, meaning to cherish and give special loving attention.

\section{Method}

\subsection{Design}

The study uses an exploratory qualitative design, in which qualitative data are collected, based on real-life experiences brought out in focus group discussions. Focus groups were selected for enhancing the dynamics of discussions and ensuring that different perspectives would be expressed. The interactions and dynamics among focus group members can generate important information in a data collection situation, which most notable would be less accessible without the focus group interaction.

Table 1. Description of Watson's caritas processes and focus group themes.

\begin{tabular}{|c|c|c|}
\hline Watson's Carative Factors & Watson's Caritas Processes & Focus Group Themes \\
\hline Humanistic-altruistic values & $\begin{array}{l}\text { Practicing loving-kindness \& } \\
\text { equanimity for self and other. }\end{array}$ & \\
\hline Instilling/enabling faith \& hope & $\begin{array}{l}\text { Being authentically present to/enabling/sustaining/honoring } \\
\text { deep belief system and subjective world of self/other. }\end{array}$ & \\
\hline $\begin{array}{l}\text { Cultivation of sensitivity to } \\
\text { one's self and other }\end{array}$ & $\begin{array}{l}\text { Cultivating of one's own spiritual practices; } \\
\text { deepening self-awareness, going beyond "ego self". }\end{array}$ & \\
\hline $\begin{array}{l}\text { Development of helping-trusting, } \\
\text { human caring relationship }\end{array}$ & $\begin{array}{l}\text { Developing and sustaining a helping-trusting, } \\
\text { authentic caring relationship. }\end{array}$ & REVERENCE/RESPECT \\
\hline $\begin{array}{l}\text { Promotion and acceptance } \\
\text { of expression } \\
\text { of positive and negative feelings }\end{array}$ & $\begin{array}{l}\text { Being present to, and supportive of, the expression of } \\
\text { positive and negative feelings as a connection with } \\
\text { deeper spirit of self and the one-being-cared-for. }\end{array}$ & $\begin{array}{l}\text { DIGNITY-VALUE OF } \\
\text { HUMAN LIFE }\end{array}$ \\
\hline $\begin{array}{l}\text { Systematic use of scientific (creative) } \\
\text { problem-solving caring process }\end{array}$ & $\begin{array}{l}\text { Creatively using presence of self and all ways of } \\
\text { knowing/multiple ways of Being/doing as part of the } \\
\text { caring process; engaging in artistry of caring-healing practices. }\end{array}$ & $\begin{array}{l}\text { BONDING } \\
\text { SENSITIVE TO SELF } \\
\text { AND OTHER }\end{array}$ \\
\hline $\begin{array}{l}\text { Promotion of } \\
\text { transpersonal teaching-learning }\end{array}$ & $\begin{array}{l}\text { Engaging in genuine teaching-learning experiences that } \\
\text { attend to whole person, their meaning; attempting to } \\
\text { stay within other's frame of reference. }\end{array}$ & $\begin{array}{c}\text { GOOD } \\
\text { COMMMUNICATION } \\
\text { COMPETENCE }\end{array}$ \\
\hline $\begin{array}{l}\text { Provision for a supportive, protective, } \\
\text { and/or corrective mental, social, } \\
\text { spiritual environment }\end{array}$ & $\begin{array}{l}\text { Creating healing environment at all levels } \\
\text { (physical, non-physical, subtle environment of energy } \\
\text { and consciousness whereby wholeness, beauty, } \\
\text { comfort, dignity and peace are potentiated. }\end{array}$ & $\begin{array}{l}\text { WILLFULNESS } \\
\text { DEEP CARING }\end{array}$ \\
\hline $\begin{array}{l}\text { Assistance with } \\
\text { gratification of human need }\end{array}$ & $\begin{array}{l}\text { Assisting with basic needs, with an intentional, caring } \\
\text { consciousness of touching and working with } \\
\text { embodied spirit of individual, } \\
\text { honoring unity of Being; allowing for spiritual emergence. }\end{array}$ & \\
\hline $\begin{array}{l}\text { Allowance for } \\
\text { existential-phenomenological } \\
\text { spiritual dimensions }\end{array}$ & $\begin{array}{l}\text { Opening and attending to spiritual-mysterious, } \\
\text { unknown existential dimensions of life-death; } \\
\text { attending to soul care for self and one-being-cared-for. }\end{array}$ & \\
\hline
\end{tabular}




\subsection{Focus Group Protocol and Participants}

Purposeful sampling included post bachelor students in cancer nursing, nephrology nursing, pastoral counselling, public health nursing, and Masters' students in community health nursing attending a university college in southeast Norway. Participants were recruited by the researcher (MK) who visited classes at this institution and explained the purpose and procedure of the study at the beginning of their classroom lectures. Six focus groups were conducted and included the following: pastoral students $(\mathrm{n}=4)$, two groups of nephrology students $(\mathrm{n}=4, \mathrm{n}=5)$, a combined group of public health nurses and pastoral students $(n=8)$, and two groups of cancer students $(n=4, n=6)$ were held between April 2016 - December 2016. Focus groups were conducted in a quiet room at the same university. Students were welcomed upon arrival and refreshments were served. The time span of the focus group sessions were between 40 minutes to one hour in length. Both authors served as moderators where one led the questioning and the other observed verbal and non-verbal interaction. The first part of each session was used to provide ground rule information, remind participants about ethical considerations, and obtain written informed consent and sociodemographic information. Oral consent was also given to tape record the sessions. A short list of standardized questions and prompts were formulated in advance to move the open discussion. Open-ended questions included: "When you think of the word professional care, what comes to mind?" "When you think of the term good care, what do you think about? Can you give some examples?" "What factors contribute to being able to give good care?" "Do you believe there is a difference in levels of caring, such as deep caring and just caring? Can you give some examples?" "When you feel that you have given good care, what consequences does this have for you?" At the closure of the focus groups, the moderator summarized the main points of the discussion, in order to verify the accuracy of the information discussed. At this time, participants were also asked to add other comments if needed, as well as express their views regarding the discussion. Field notes were written immediately after each focus group to document impressions, themes, and group interactions. None of the students recruited from classes decided to withdraw from the study after agreeing to participate.

\subsection{Ethical Considerations}

The study was approved by the research committee at the institution where the study took place. Participation was voluntary. Students were told that their refusal to take part in the study would have no consequences for their studies. Written consent to take part in the study was obtained and oral consent was given at the beginning of the focus groups to tape record the sessions and use the results in publications. An agreement was made that the tape recorder would be turned off during parts of the dialogue, if desired. Participants also received the email address and phone number of the researcher (MK) in case there was a 
need for contact.

\subsection{Data Analysis}

Audio recorded interviews were transcribed in full by a professional transcriber and then translated into English by the researcher (MK). After all the six interviews were conducted, the analyses started with reading the transcribed interviews simultaneously in order to get a feeling of the whole. This holistic approach was taken in order to discern an overall and fundamental meaning of the experiences. Each interview was then condensed by highlighting passages of importance to the investigated phenomenon; by the first author (MK). This started a process of reflection and search for meaning in the text by extracting essential themes. Van Manen [34] calls this thematic analysis. In this analytic step, a list of preliminary themes was constructed, by highlighting phrases and quotes that seemed to be thematically related to professional caring. This step continued with refection over the themes by viewing them in light of each interview and the issues of interest as related to the open ended questions. In the process, the preliminary themes were constructed inductively into a hierarchy so that categories were grouped into sub-themes and themes into essential themes. The second author then reviewed all steps in this process, also searching for evidence that contradicted and as well conformed to this process [35]. Afterwards, critical discussion ensued until both authors were in agreement regarding major themes, subthemes and exemplars. This procedure was an interpretative creative process and findings evolved as a result of an intuitive and reflective writing process. This process can be understood as a circular process occurring between reading and re-reading the transcribed interviews, viewing the themes in their own context, and writing and re-writing towards a higher level of abstraction. At the end of this process, the themes were supported by quotations from the interviews to enhance credibility. To enhance the validity of the categorizing method and to guard against bias, a list of themes, subthemes and quotations were then presented to colleagues at the institution where the study took place. These colleagues were invited to discuss the naming and classification of the themes and sub-themes, searching for confirmation as well as contradictions to enhance the reliability of the findings. Cultural and historical influences were also discussed at this meeting as both researchers have English as their mother tongue, residing in Norway since the 1970's.

\section{Results}

\subsection{Sociodemographics}

Of the 32 students, the majority were women $(\mathrm{n}=29,93 \%)$ with only 2 men participating (6.45\%). A large proportion were middle aged (40 - 60 years) and had worked over 15 years. Twice as many of the students were working full time as compared to half time and the majority were married with children. Refer to Table 2. 
Table 2. Sociodemographic characteristics of the focus groups.

\begin{tabular}{|c|c|}
\hline Variable & Number \\
\hline Number of participants & 31 \\
\hline \multicolumn{2}{|l|}{ Gender* } \\
\hline Women & 29 \\
\hline Men & 2 \\
\hline \multicolumn{2}{|l|}{ Age $^{*}$} \\
\hline \multicolumn{2}{|l|}{$20-30$} \\
\hline$>30-40$ & 4 \\
\hline$>40-50$ & 7 \\
\hline$>50-60$ & 10 \\
\hline$>60$ & 9 \\
\hline \multicolumn{2}{|l|}{ Marital Status* } \\
\hline Unmarried & 0 \\
\hline Married & 3 \\
\hline Living together & 19 \\
\hline Divorced/separated & 6 \\
\hline Widowed & 1 \\
\hline \multicolumn{2}{|l|}{ Educational Background } \\
\hline Nursing & 27 \\
\hline Counselling & 3 \\
\hline \multicolumn{2}{|l|}{ Years Working* } \\
\hline $1-5$ & 2 \\
\hline$>5-10$ & 6 \\
\hline$>10-15$ & 3 \\
\hline$>15$ & 4 \\
\hline \multicolumn{2}{|l|}{ Working \% } \\
\hline Full time & 16 \\
\hline Half time & 15 \\
\hline Other & 1 \\
\hline \multicolumn{2}{|l|}{ Children* } \\
\hline Yes & 22 \\
\hline No & 4 \\
\hline
\end{tabular}

${ }^{*}$ Missing answers.

\subsection{Qualitative Findings}

Findings revealed that the concept of care could be categorized into seven main themes: 1) reverence and respect for the dignity and value of human life; 2) bonding; 3) sensitive to self and others; 4) communication; 5) competence; 6) willfulness; and 7) deep caring with 44 sub-themes. An overview is presented in Table 3.

Reverence/respect for the dignity and value of human life

A major theme that consistently emerged throughout the focus groups was 
Table 3. Major themes and sub-themes found in focus groups regarding professional care.

Reverence/respect-dignity and value of human life

humane, spirit

holistic

moral stance

wishing the good

compassion

appreciating uniqueness

wisdom, gratitude, personal growth

\section{Bonding}

full presencing, authentic, open

affirmation, attentive, concerned

trusting, kind, near

wishing good

security, confidence

consciousness

courageous

Sensitive to self and other

intuition, insight

focused awareness

centered self-other

personal characteristics and reactions

professional identity

self-reflection

cultural sensitivity

\section{Communication}

dialogical

listening and questioning

finding opening

non-invasive, non-judgmental

confidentiality, accepting boundaries

accepting own limitations

word use

\section{Competence}

information

enhance autonomy

respecting beliefs, concerns, wishes

setting expectations, boundary setting

professional skills

collaboration, teamwork

advocacy

\section{Willfulness}

intentional, initiative

choice, decision making

creating challenges, see alternatives

commitment

concern

pacing

expressing feeling

Deep Care

little extra's

sacred acts 
reverence and respect for the dignity and value of human life. This included appreciating the humaneness and spirit of others, which also featured seeing the whole person and not the disease, and revering the client as a human being as illustrated by the following comment: "You see the whole person and their needs and not just the disease; one sees the human being in the patient. This is so important, maybe even talk about other things than their illness." Reverence and respect also embraced a moral stance by wishing the good and best for others, based on caring actions representing the good. The importance of compassion and empathy were often mentioned by attempting to place oneself in the others' situation and reflecting over how one would feel, if for example, one had to spend life in bed or felt like a prisoner in a room. Various comments included: "Every day you are in a different situation, many which are complex and changing. One has to try to place oneself in the other's situation and think how would I feel if someone spoke to me like that or neglected to acknowledge me?" "It is so important to acknowledge the other as a valued human being. For example, a homeless on the street, how would he feel if I approached him with holes in my clothes?" and "I believe after a patient has died that bathing the body should be done with quietness and a sense of respect. I also speak softly. I often visualize that the person who has just died is up under the ceiling and watching how I am caring for his dead body." Many discussed dignity and value which included respect for the uniqueness of the other, respecting their needs and encouraging self-respect. Looking directly into the other person's eyes, anticipating needs before the need to ask, respecting family needs and roles, and respecting the space people needed were also regarded as essential to caring. Other features related to reverence and respect included feelings of gratitude, enhanced wisdom and personal growth as outcomes of close relationships. One participant said: "Good caring is feeling that you have succeeded with something that has been your aim in the relationship. For example, when working with depressed teen-agers and you note a small change in their humor during the consultation. This is a very, very good feeling." Also, the importance of organizational standards and ethical guidelines were mentioned as grounding one's reverence and respect for the dignity and value of human life.

\section{Bonding}

The theme bonding embodied full presencing with authenticity which included being open, trusting, kind and near and for some, also included the aspect of love as illustrated by the following comment: "One has to accept that one doesn't always find the best solutions, and that one doesn't have an answer to everything. For example, one can say I can't help you with this and I don't have an answer to your question. One needs to be honest and this is related to the trust you have established and your way of being." Features of bonding embraced affirmation, being attentive, accepting and showing concern based on a wish for doing the best for the other. "Some patients don't know what they need. But if I listen to my gut feeling I can sense a strong bond with the patient with feelings of closeness that I mean something to this patient." Bonding also in- 
cluded showing that one cares even though there is little one could do in the situation by giving signals that one wished to share the suffering with the other. One verbalized. "Some patients invite us in to be closer to them. I had a young patient with cancer. I looked at him closely and took the initiative to ask him why he couldn't sleep. He said he was very scared he would die. I was concrete with him in saying that death doesn't happen more often when you are sleeping than when you are awake. He then asked if I could stay there with him and pray. And I did just this. Afterwards I left the door a bit open so he could feel more secure." Creating a sense of confidence and security, being conscious of the way one observes and speaks to the other, having tolerance and not taking over tasks for the other and giving distance so that a sense of autonomy could be maintained were also deemed important. Bonding also included courage to be the person one is, courage to help each other as colleagues instead of resignation, courage to make decisions and say no to patients when there is a risk to their health and quality of life were also discussed. Further, using one's senses, so that one can do what was right and needed at the moment were also perceived as representative of caring. As illustrated by these comments: "For me, care is being present in the moment, capturing the need in the moment. Also, the way you observe and look at the other, the way you speak to other people" and "Caring is also respecting that your client doesn't want to do what you recommend, but one can say I'm here if you decide differently. That we are willing to give them room not to need us and at the same time we keep an eye on them."

\section{Sensitive to self and other}

The theme sensitive to self and other embodied a form of authentic comportment including features such as intuition, insight and focused awareness, taking quiet moments to center, being open to one's senses, questioning why one is here, being conscious of professional identity and power in relationships, knowing one's own boundaries and not performing tasks one is not qualified to do. Other features embraced consciousness of one's personal characteristics and reactions, and realizing that everyone is always communicating something in body and appearance. The following comments illustrate these points: "I reflect sometimes over why I feel that I have given good care, what impacted this and what happened in this situation?" and "If we are going to make any difference in this world, it is best that we begin with our own self, because you are with your own self twenty-four hours a day." Others said, "One has to get back to the basics, to one's own emotional register." "I need to be conscious of my own reactions, how do I manage my anger and what do I do with that feeling?" Cultivating caring consciousness toward self and others by creating rooms for reflection, supervision, and education, being conscious of one's own needs for care, and self-retreat were also considered important. Being sensitive to another also involved cultural sensitivity and being conscious of cultural differences, questioning one's own cultural beliefs, and respecting the others' beliefs systems. This also embodied not forming preconceived judgements based on information received from others as shown by these comments: "I had a patient from a differ- 
ent culture who had to have dialysis and she would not accept having a leg amputation even though her toes were almost falling off. She believed in voodoo. We tried to convince her that this was for her best but she was totally against it. In the end we had to respect her wishes and she died earlier than she would have if she had undergone the operation. But I mean this is also caring because her belief was so important to her." "It is easy to have images of a person you don't know from the histories you have heard. For example, that they have used drugs or have mental problems and you make up your mind about who the other is and how they are going to act, before you meet them."

\section{Competence}

The theme competence was considered by the majority as an integral part of care. This included gathering information through one's senses, which help people form decisions, discover alternative goals, and giving encouragement in meeting these aims. "It is important to set boundaries, to reflect upon how close is it wise to be. To think how much self-care does this person need so they maintain their self-respect? One must be conscious about not setting too rigid boundaries, so that others can't get close to you and move you within." This issue also embraced enhancing autonomy, and allowing people to live their own lives based on their own beliefs, needs, concerns, and wishes. Competence also enclosed trying to discover what is most important to the unique individual, simply asking how they could be helped, and setting expectations and professional boundaries as some patients couldn't care for themselves. Competence also embodied the use of professional skills such as updating knowledge and clinical skills as exemplified by this comment: "I try to gain updated knowledge and professional skills so that I know what I am doing." "Caring competency comes from experience. As a novice, one is unsure and asks what have I done wrong now? One takes the clients' comments more personally because one is vulnerable. Now after many years of experience I can say to the client, of course we can do this differently if this is best for you." Planning ahead, such as not discharging people too early when possible, and the importance of collaboration, teamwork and delegating responsibility were deemed important as shown by the following comments, "Caring depends on the colleagues you are working together with on a specific day. With some, you work quietly together and it is like moving together on train tracks where everything runs so smoothly. While other days, things go roughly because you are working with someone you don't share good energy with and there is a lot of complaining" and "One observes vulnerability in the other, and then works together as a team, starting a documentation process early. Good care begins on an abstract level and moves downward towards more selective actions." Further, client advocacy was also mentioned as an important aspect of care and caring.

\section{Good Communication}

The theme communication embodied the importance of shared dialogue grounded in listening and questioning. This embraced trying to find an opening so the other could find words as illustrated by the following comments: "You 
find the good moment when you feel here and now we can talk about something that it difficult and we grasp that moment which may have had to do with pain or anxiety and on a different level. You just sense something and the words just seem to flow-it's not that so many words need to be said, but it is so beautiful when it happens" and "I think that if you have respect for each person you meet, caring evolves in your relationship with the other. One asks what one truly needs; one takes time to develop good communication between the two of you." Of importance to communication, was also not having a high-down attitude, not being invasive and discriminating, and understanding that language has power in itself. Other interpretations included being non-judgmental, not using a pitying attitude, and not being condemning, as for example, thinking that the client's condition is their own fault. Good communication was also regarded as being based on confidentiality and accepting patients' boundaries. Other views involved not using empty words like stating "everything will be okay", and not giving false hope. Good communication also entailed giving support to help the other find the right words.

Willingness

The theme willingness included a will to give by creating intentions and caring through intentional acts as exemplified by these comments: "Caring is related to the intentions, thoughts, feelings and wishes which are behind the gestures. It is not the touch itself, but the intention that is shown through the gesture." Another said: "I take an extra initiative when the client doesn't come for his appointment. I check whether he was at school that day, try to find the reason he didn't come, and if something special has happened. This little extra shows I really care about him and his situation." "Other features related to this theme included taking initiative in caring relationships, increasing participatory choices and decision making, respect for nearness and distance, creating challenges and helping the other see and understand alternatives." One participant said: "I have to watch myself that I don't take over the situation as this can happen quite easily. I must be aware that I do not do things for the patient which they are quite capable of doing themselves even though it takes longer time." This also embraced showing commitment, kindness, concern and the expression of feelings as shown by the following: "Caring is giving, instilling in others a belief that they can cope with what they are going through, it is creating challenges and giving encouragement."

\section{Deep Caring}

The theme deep caring embodied a deep level of comportment and caring consciousness. It seemingly embraced a sense of loving care which was exemplified in a form of intensity of being present in the moment with sensitivity, understanding and concern. It was evidenced by ethical imperatives, consciousness of the small steps needed to journey together with the ability to break through barriers in capturing the moment. Some participants said: "Deep caring involves a spiritual dimension. I use the word love, it is the way in which I move the other's body with gentleness, and this is the difference between caring and loving." 
Deep caring also includes a greater flexibility in demanding situations and being on the giving side, as reflected by these comments, "It is being present in the moment, being near, you don't need to hold a hand or move anything, you are simply there, ... just taking a bit more time," "We are not taking about ethics, but instead, what is good nursing right there and now, we're talking about the moments when you sense we can talk about what is difficult exactly now." Another stated: "Caring is having responsibility and there are different responsibilities in varied situations. One sees that someone is in need and simply tunes in on a deeper level." Others described this feeling as the following, "She placed her hand on my shoulder and I could almost feel her caring concern, what was behind this gesture I am unsure, but I felt she really cared." Other comments included "Some patients move you more than others-why this is, can be questioned, one feels more deeply, but it is not conscious." and "There exists good chemistry and bad chemistry, it is easier to give a little extra to those you have good chemistry with, than those who are difficult."

Deep caring was also reflected in offering the little extras or what Watson may refer to as scared acts. This was described as creating an atmosphere by offering little things, a cup of tea, lighting a candle, bending down to tie a shoelace, setting a table in a place where the other won't be observed crying or be disturbed by telephones, a little touch on the shoulder, showing silent gratitude, and simple questions like "how are things going for you?" Other descriptions included placing a glass of water within reach, taking an extra trip into the patient's room because you know they need it, sitting down, listening intently and using time to discover more, moving a pillow and hearing the sigh of relief. Deep caring was also connected to the ward atmosphere-where one gives the little extra to each other, to one's self and to clients, which in turn, created energy.

Participants also discussed the consequences of performing deep caring acts: "It is easier to try again, it creates good feelings, you feel you have succeeded in something and have made a difference." Another said, "For the patients, good caring means a lot, they feel secure, valued and less a burden, and one has created an opening where a change has taken place. I feel happy because there is a positive outcome for the other, and this contributes to my professional growth, I feel I have done a good job."

\section{Discussion}

In this study, we explored the different meanings given to the concept of professional care by post graduate nursing and pastoral students. The results included seven main themes which included reverence and respect for the dignity and value of human life, bonding, sensitive to self and other, communication, competence, willfulness and deep caring and 44 sub-themes.

\section{Reverence and Respect for the Dignity and Values of Human Life}

Watson has earlier described caring as "moral ideal" rooted in humanistic values of caring with the ultimate goal of treating other people with respect and dignity ([33], p.54). Watson's beliefs also greatly emphasize the importance of 
intentionality. This is described as aligning one's consciousness with co-interconnectedness which displays a commitment toward the other which conveys reverence, respect, compassion, and authenticity. A major theme from our findings included the importance of reverence and respect for the dignity and value of human life which support these contentions. Respect, as an essential component of care, has been well documented in other studies [5] [36] [37] [38]. Dialogue was also centered on the importance of recognizing and appreciating the humanness, wholeness and uniqueness of the other with feelings of compassion. These caring attributes are also well documented [39]-[47]. Further, notions of the good and wishing the good for the other were discussed. We found this particularly interesting as in a recent systematic review on the concept of care, this quality received little weight [48]. These finding may be related to the institution where our study was conducted which supports spiritual values.

\section{Bonding}

Watson also describes conscious intentionality as holding thoughts that are caring, loving, open, kind and receptive, in contrast to an intentionality to control, manipulate and have power over [49] which was also conveyed in our findings. The importance of bonding, being present and authenticity were also discussed as supported by others [40] [44] [50] including MacNeil and Evans' [28] research with students. Bonding was also characterized by such attributes as openness, affirmation, attentiveness, concern, trust, kindness and nearness, also evidenced in the literature [5] [44] [51]. Likewise, aspects of consciousness, confidence and protection were deemed important as supported by others [40] [51] [52]. Smith [52] has described the concept of presence with such attributes as genuine dialogue, commitment, full engagement, openness and attentiveness, similar to our findings. Notably, supporting Watson's views on intentionality to control, dialogue also centered on characteristics of not being judgmental, not being invasive and being cognizant of word use in labelling others. Others have also described the need to be daring and firm with consideration of one's attitudes toward the other and positioning within the relationship also verbalized by our participants [5] [43] [53].

Sensitive to Self

Caring consciousness has been described by Watson [54] as being open to new and expanding experiences with a depth of reflective and emotional capabilities. This openness contains the ability to be real, honest and authentic and is based on self-knowledge and openness to feelings. A major theme that emerged in our findings was the importance given to sensitivity, both sensitivity to self and sensitivity to others. This sensitivity included such qualities as forms of intuition, focused awareness, self-reflection, and emotional adaptability. These themes underline the importance of remaining emotionally close to one's own vulnerability in the common experience of being human. All these themes have been supported in the literature on caring [5] [42] [43] [45] [47]. The importance of having cultural sensitivity was also underlined. This is important consi- 
dering other studies involving students have reported observations where nurses appear reluctant to provide care to ethnic minorities [55] [56]. Lack of cultural competence was also perceived by students to be a barrier to learning about caring [57].

Further, Watson views empathy as the key to developing healing-trusting relationships [55]. Results also underlined the importance of this attribute as documented by others [5] [38] [42] [43] [45] [58]. Empathy can be regarded as the ability to sense the inner world of another which requires that the carer is aware of their own inner world while also creating a common emotional meeting ground. As such, one needs to tune into one's experiences with uncertainty, anger, sadness, joy, love, etc. which creates the capacity for becoming sensitive to another's emotional state and needs [55]. Our carers' described the necessity of "tuning in" to the other, as also vital to caring, as confirmed by others [42]. Other studies have also described experiences of joy, cherishing and love [40] as well as anger, weariness and irritation among carers [5]. The aspect of love was also underlined by Greek students [27].

Communication

Caring presence and intentional resonance focus on trying to understand what is meaningful and of concern in the lives of the other. Such a presence incorporates reflections on meanings, events and needs so that new meanings can be formed from disrupted meanings. Such meanings cannot be uncovered without good communication which the majority of participants often described. Good communication includes such aspects as attentive listening and questioning, finding openings, confidentiality, accepting the others' boundaries and self-limitations which have been confirmed by others [5] [40] [43] [47] [58] [59] [60]. As evidenced by our findings, invitation to dialogue also embodies recognition of the other, invites affirmation and trust, and fosters security and confidence, also with the intent of wishing the good or the best for the other. In this mutual process, the self and other are engaged in an experience which includes attention, acceptance, concern which potentiates insight, also supported by others [5] [42] [51].

Competence

Within a transpersonal caring moment, the carer enters into, and stays within, the other's frame of reference. Our results also underlined the importance of respecting the beliefs, needs, and wishes of the other. This human-to human interaction includes the totality of human experience, composed of perceptions, feelings, intentions, thoughts, goals, environmental impacts and for some, spirituality and love [61]. The meaning of one's perceptions also depends on observations, feelings, imagination and understanding which are reflected in the carer's professional competency. Such competency entails communication of critical information accurately and timely and is also essential for problem solving with colleagues. It also enhances autonomy, forms expectations, and incorporates collaboration and advocacy as professional skills. Aspects of knowledge and skill were also important to students in Papastavrou and colleagues [30] re- 
search. These characteristics seemingly support the idea of promoting partnership and freedom of choice by attempting to stay within the other's frame of reference. All these qualities as essential to care have been documented by others [5] [38] [40] [42] [43] [47] [51] [59] [62].

\section{Willfullness}

Intentionality involves consciousness and awareness directed toward a mental object, with purpose and efficacy toward action, expectation, belief, volition, and even the unconscious [49]. Our results also underlined the importance of willfulness as a form of intentionality in taking initiative, being committed, sharing choices and decisions, creating challenges and helping the other see alternatives as being paramount, which may be interpreted as demonstrating a willingness to share power. Further, pacing and the expression of feelings can be understood as characteristics of intentionality as supported in other studies [5] [38] [44] [45] [58].

\section{Deep Caring}

Different levels of intentionality, action, and caring consciousness were revealed in the discussions. Some carers discussed caring acts which we have termed "deep caring". These acts seemingly reflect what Watson describes as the emergence of caring and love coming together in a transpersonal caring moment. "Deep caring" also focuses on grasping the experience of deeper and more spiritual concerns that emanate from the personal and intersubjective ([63], p.5). These acts were portrayed by a willingness to move into moments with a deep intentionality and consciousness. In "deep caring" there seems to be a transforming presence formed, where one grasped the moment, which involved letting go of time constraints, putting other tasks aside, and focusing completely on the other's instant need. This aspect of time as embedded with moral meaning was also confirmed by students in Dabrowolska and colleagues [26] study. "Deep caring" was also shown by taking time to offer the little extras, or what Watson refers to as sacred acts, such as placing a glass of water within reach, listening intently and using time to discover more, or simply moving a pillow and hearing the sigh of relief. Others have also described similar nursing acts as being deeply involved and going beyond routine [5] [38] [42]. These acts seeming support DeQuincey's [64] contention which states "Being intensely engaged in a relationship with another... is perhaps the most vital manifestation of consciousness. It requires a shift from a world of subjects-objects to a view which sees the relationship as fundamental." As authors we believe the provision of these little extras may represent the energy of caritas processes all merged into one substance.

Study findings may attune to what is described as professional comportment as a quality interrelated with intentionality and caring consciousness. Professional comportment, as one's demeanor and bearing, has been described as determining a carer's effectiveness in relating, communication and collaboration which includes self-regulation and individual accountability. This in turn, promotes mutual respect, commitment and harmony [65]. Others such as Benner 
and colleagues [66] describe professional comportment as including the nurses' words, intents, beliefs, values, stance, touch, physical presence and actions together with the assimilation of abilities, knowledge, interpersonal effectiveness and communication with members of the healthcare team and patients. Professional comportment can also be understood as encompassing the carer's sentience (perceptions, senses, conscious mind) as represented in sentient embodiment [67]. We believe our findings witness to these attributes.

Our findings also lend support to many of the major beliefs and values in Watson's Human Caring Theory and the description of her caritas processes which focus on caring consciousness grounded in deep connectedness, of relationship and mutuality, subjective meaning and shared humanity. This perspective also embodies moral commitment, intentionality, and authenticity which are essential in enhancing human dignity and wholeness. Such a perspective supports intentionality and caring consciousness as deeply embracing energy and spirit as exemplified in what we described as "deep caring" moments [49]. These beliefs support a moral stance based on reverence and respect for the value and uniqueness of other and self and the uniqueness of the moment in human-to human caring transactions.

\section{Limitations}

The study is limited because of convenience sampling and a small sample consisting of a majority of women, although their age spans differed greatly. Furthermore, participants were recruited from only one institution though they lived and worked in many geographical areas in Norway and had backgrounds in community health nursing, cancer nursing, nephrology nursing, public health nursing and pastoral care. The names given to the major themes and sub-themes were discussed by two independent researchers, yet the selected terminology used in classifying themes and sub- themes denote specific nursing knowledge. However, interpretations of the themes and sub-themes were reviewed by inviting colleagues with different expertise and backgrounds to review the results. Watson's Human Caring Theory used in this study may have biased the researcher's interpretation of findings. It should also be noted that this theory is not a part of the curriculum in nursing or pastoral care at this specific institution, although the institution is grounded in Christian ideals. Notably, it has been reported that the dynamics of focus group interactions are seldom reported in presenting focus groups results [68]. As such, group dynamics may also introduce bias to the study, also threatening the trust worthiness of the findings. Therefore, a short description of the group dynamics is included inconsideration of the study's limitations.

The moderators had previous experience with conducting focus groups. The moderators played a more passive role, using probes when needed, but allowing discussion to evolve openly. Because all of the groups had been recruited in their own classrooms, the atmosphere of the groups portrayed a sense of group membership and cohesiveness. Notably, research has shown that there is a tendency 
for more self-confident and articulate individuals to be more willing to agree to take part in focus groups [69]. In two of the groups, certain members were more assertive and as a result the more silent participants had to be invited into the dialogue. Also, in groups where there were a majority of older participants, the younger tended to be less articulate. Tape recording the sessions, could have caused feelings of unease for some, and one group commented that it would have been easier to speak together without the tape recorder. Some groups had participants who talked all at once and many of the groups used laughter when participants were in agreement with what was being described. However, both divergent and similar views were aired in all of the groups. Interestingly, some of the most valuable information was discussed towards the end of the group, which could be related to the fact that the participants felt safe and were more at ease. It was also interesting to note that when the groups were formally closed and the tape recorder turned off, discussion could ensue with a few participants.

\section{Implications for Nursing}

The goal of holistic nursing practice is to treat and heal the whole person-by recognizing the interconnectedness of body, mind, spirit, and environment. By exploring the meanings given to phenomenon of professional care, findings revealed ways in which the whole person was shown respect, revered and treated in differing intensity. The interactive discourses generated valuable detail of complex experiences and beliefs, behind participant's perceptions, attitudes, beliefs and actions. They also illustrated both practical and moral reasoning and skilled ethical comportment which are cornerstones in practicing holistic care.

We believe focus group methodology can enhance holistic nursing practice by providing opportunities to explore and clarify holistic care values on many levels by creating opportunities for holistic self- development and awareness, group interaction and transformative learning in many arenas such as in education, practice, administration, research, health care theory and model development.

A vast array of studies, also cross culturally have shown that Watson's Human Caring Theory can inform holistic practice. Numerous institutions and health care facilities have since adopted her theory as a guide to change their own nursing practice. Although a small study, our findings also affirm some of the major beliefs and descriptions of the caritas processes underlined in her theory.

Of importance to holistic nursing, is the fact that various studies have shown that nurses' and patients' views differ in what they view as important in caring. Nurses have been found to perceive expressive behaviors like providing trusting relationships, listening and comfort as most important, as compared to patients who assign higher importance to instrumental, technical caring activities and information [70] [71] [72] [73]. Recently, Papastravrou and colleagues [30] conducted a systematic review of 23 quantitative studies focused on nurses and patients' perceptions of caring behaviors where they also found evidence of incongruence in patient and nurse perceptions. Findings showed that patients valued instrumental, technical caring skills which demonstrated competency and 
"know how" as being more important than nurses. Nurses, on the other hand, perceived affective caring behavior as more important than patients. In a crosscultural study of six different EU countries which explored the concept of caring through nurse behaviors, important differences were observed between patients' and nurses' perceptions of caring behaviors. Perceptions related to assurance of human presence, knowledge and skills, respectful deference to others and positive connectedness was widely diverse. Further, Watson also found that listening to patients scored as the most caring of all tasks for nurses, whereas patients on the other hand rated most highly being involved in care and providing privacy [49]. Such findings highlight the need for future holistic nursing studies which assess nurses, patients' and families' perspectives regarding what they perceive as important caring behaviors. Culture and holistic care are embedded in each other, consequently, holistic caring needs to be understood in a cultural context, also in future comparative studies.

\section{Conclusion}

The results of this study demonstrate a congruence between some of the major beliefs and caritas processes in Watson's Human Caring Theory and the meanings given to professional care as described by post graduate nursing and pastoral students. The themes of reverence and respect for the dignity and value of human life, bonding, sensitive to self and others, communication, competence, willfulness, and "deep caring" together with their sub-themes lend support to these beliefs. Results also show that professional comportment, intentionality and caring consciousness are reflected in varied intensity and depth.

\section{References}

[1] Pettersen, T. (2011) The Ethics of Care: Normative Structures and Empirical Implications. Health Care Analysis, 19, 51-64. https://doi.org/10.1007/s10728-010-0163-7

[2] Leininger, M.M. and McFarland, M.R. (2006) Culture Care Diversity and Universality: A Worldwide Nursing Theory. 2nd Edition, Jones and Bartlett, Sudbury.

[3] Swanson, K.M. (1991) Empirical Development of a Middle Range Theory of Caring. Nursing Research, 40, 161-166. https://doi.org/10.1097/00006199-199105000-00008

[4] DiNapoli, P.P., Nelson, J., Turkel, M. and Watson, J. (2010) Measuring the Caritas Processes: Caring Factor Survey. International Journal for Human Caring, 14, 1621.

[5] Finfgeld-Connett, D. (2008) Meta-Synthesis of Caring in Nursing. Journal of Clinical Nursing, 17, 196-204.

[6] Swanson, K.M. (1999) What Is Known about Caring in Nursing Science: A Literary Meta-Analysis. In: Hinshaw, A.S., Feetham, S. and Shaver, J., Eds., Handbook of Clinical Nursing Research, Sage Publications, Thousand Oaks, 31-60. https://doi.org/10.4135/9781412991452.n3

[7] Watson, J. (2008) Nursing: The Philosophy and Science of Caring. Revised Edition, University Press of Colorado, Boulder.

[8] Benner, P. and Wrubel, J. (1989) The Primacy of Caring: Stress and Coping in Health And Illness. Addison-Wesley, Menlo Park. 
[9] Dahlberg, K., Todres, L., and Galvin, K. (2009) Lifeworld-Led Healthcare Is More than Patient-Led Care: An Existential View of Well-Being. Medicine, Health Care \& Philosophy, 12, 265-271. https://doi.org/10.1007/s11019-008-9174-7

[10] Dahlberg, K., and Segesten, K. (2010) Hälsa och vårdande: I teori och praxis. Natur och Kultur, Stockholm.

[11] Eriksson, K. (2001) Vårdvetenskap som akademisk disciplin. Åbo Akademi, Vasa.

[12] Levy-Malberg, R., Erikkson, K. and Linholm, L. (2008) Caritas-Caring as an Ethical Conduct. Scandinavian Journal of Caring Sciences, 22, 622-627.

[13] Ray, M.A. (1989) The Theory of Bureaucratic Caring for Nursing Practice in the Organizational Culture. Nursing Administration Quarterly, 13, 31-42. https://doi.org/10.1097/00006216-198901320-00007

[14] Watson, J. (1997) The Theory of Human Caring: Retrospective and Prospective. Nursing Science Quarterly, 10, 49-52. https://doi.org/10.1177/089431849701000114

[15] Paterson, B. and Crawford, M. (1994) Caring in Nursing Education: An Analysis. Journal of Advanced Nursing, 19, 164-173. https://doi.org/10.1111/j.1365-2648.1994.tb01064.x

[16] Murphy, F., Jones, S., Edwards, M., James, J. and Mayer, A. (2009) The Impact of Nurse Education on the Caring Behaviours of Nursing Students. Nurse Education Today, 29, 254-264. https://doi.org/10.1016/j.nedt.2008.08.016

[17] Ma, F., Li, J.P., Liang, H.M., Bai, Y.J. and Song, J.H. (2014) Baccalaureate Nursing Students' Perspectives on Learning about Caring in China: A Qualitative Descriptive Study. MMC Medical Education, 14, 42. https://doi.org/10.1186/1472-6920-14-42

[18] Hudson, P. (2003) Focus Group Interviews: A Guide for Palliative Care Researchers and Clinicians. International Journal of Palliative Nursing, 9, 202-207. https://doi.org/10.12968/ijpn.2003.9.5.11490

[19] McLafferty, I. (2004) Focus Group Interviews as a Data Collecting Strategy. Journal of Advanced Nursing, 48, 187-194. https://doi.org/10.1111/j.1365-2648.2004.03186.x

[20] Parsons, M. and Greenwood, J. (2000) A Guide to the Use of Focus Groups in Health Care Research: Part 1. Contemporary Nurse, 9, 169-180. https://doi.org/10.5172/conu.2000.9.2.169

[21] Krueger, R.A. (1988) Focus Groups: A Practical Guide for Applied Research. Sage, Newbury Park.

[22] Morgan, D.L. (1997) Focus Groups as Qualitative Research. 2nd Edition, Sage Publications, Thousand Oaks. https://doi.org/10.4135/9781412984287

[23] Merton, R.K., Fiske, M. and Kendall, P.L. (1990) The Focused Interview: A Manual of Problems and Procedures. 2nd Edition, Free Press, New York.

[24] Dicicco-Bloom, B. and Crabtree, B.F. (2006) The Qualitative Research Interview. Medical Education, 40, 314-321. https://doi.org/10.1111/j.1365-2929.2006.02418.x

[25] Schroeder, C. and Neil, R.M. (1992) Focus Groups: A Humanistic Means of Evaluating an HIV/AIDS Programme Based on Caring Theory. Journal of Clinical Nursing, 1, 265-274. https://doi.org/10.1111/j.1365-2702.1992.tb00115.x

[26] Dobrowolska, B., Slusarska, B., Zarzycka, D., McGonagle, I., Pawlikowski, J. and Cuber, T. (2014) Care Concept in Medical and Nursing Students' DescriptionsPhilosophical Approach and Implications for Medical Education. Annals of Agricultural and Environmental Medicine, 21, 854-860. https://doi.org/10.5604/12321966.1129946 
[27] Sapountzi-Krepia, D., Lavdaniti, M., Psychogiou, M., Tsiligiri, M., Karassavdis, S., Sarpetsa, S. and Chatzi, M. (2013) The Concept of "Care" as Perceived by Greek Nursing Students: A Focus Group Approach. International Journal of Caring Science, 6, 392-401.

[28] MacNeil, M.S. and Evans, M. (2005) The Pedagogy of Caring in Nursing Education. International Journal for Human Caring, 9, 45-51.

[29] Karaoz, S. (2005) Turkish Nursing Students' Perception of Caring. Nurse Education Today, 25, 31-40. https://doi.org/10.1016/j.nedt.2004.09.010

[30] Papastavrou, E., Efstathiou, G. and Charalambous, A. (2011) Nurses' and Patients' Perceptions of Caring Behaviours: Quantitative Systematic Review of Comparative Studies. Journal of Advanced Nursing, 67, 1191-1205. https://doi.org/10.1111/j.1365-2648.2010.05580.x

[31] Begum, S. and Slavin, H. (2012) Perceptions of "Caring" in Nursing Education by Pakistani Nursing Students: An Exploratory Study. Nurse Education Today, 32, 332-336. https://doi.org/10.1016/j.nedt.2011.10.011

[32] Watson, J. (1999) Postmodern Nursing and Beyond. Churchill Livingstone, Edinburgh.

[33] Watson, J. (1988) New Dimensions of Human Caring Theory. Nursing Science Quarterly, 1, 175-181. https://doi.org/10.1177/089431848800100401

[34] Van Manen, M. (1997) Researching Lived Experience: Human Science for an Action Sensitive Pedagogy. 2nd Edition, Althouse Press, London.

[35] Marshall, C. and Rossman, G.B. (2016) Designing Qualitative Research. 6th Edition, Sage, Los Angeles.

[36] Brilowski, G.A. and Wendler, M.C. (2005) An Evolutionary Concept Analysis of Caring. Journal of Advanced Nursing, 50, 641-650. https://doi.org/10.1111/j.1365-2648.2005.03449.x

[37] Kawi, J. (2012) Self-Management Support in Chronic Illness Care: A Concept Analysis. Research Theory in Nursing Practice, 26, 108-125. https://doi.org/10.1891/1541-6577.26.2.108

[38] Wagner, D. and Bear, M. (2009) Patient Satisfaction with Nursing Care: A Concept Analysis within a Nursing Framework. Journal of Advanced Nursing, 65, 692-701. https://doi.org/10.1111/j.1365-2648.2008.04866.x

[39] Cowling, W.R. (2005) Despairing Women and Healing Outcomes: A Unitary Appreciative Nursing Perspective. Advances in Nursing Science, 28, 94-106. https://doi.org/10.1097/00012272-200504000-00002

[40] Dalpezzo, N.K. (2009) Nursing Care: A Concept Analysis. Nursing Forum, 44, 256264. https://doi.org/10.1111/j.1744-6198.2009.00151.x

[41] Hudon, C., St-Cyr Tribble, D., Bravo, G. and Poitras, M.E. (2011) Enablement in Health Care Context: A Concept Analysis. Journal of Evaluation in Clinical Practice, 17, 143-149. https://doi.org/10.1111/j.1365-2753.2010.01413.x

[42] Huynh, T., Alderson, M. and Thompson, M. (2008) Emotional Labour Underlying Caring: An Evolutionary Concept Analysis. Journal of Advanced Nursing, 64, 195208. https://doi.org/10.1111/j.1365-2648.2008.04780.x

[43] Lobchuk, M.M. (2006) Concept Analysis of Perspective-Taking: Meeting Informal Caregiver Needs for Communication Competence and Accurate Perception. Journal of Advanced Nursing, 54, 330-341. https://doi.org/10.1111/j.1365-2648.2006.03815.x

[44] Noble, H., Kelly, D., Rawlings-Anderson, K. and Meyer, J. (2007) A Concept Analy- 
sis of Renal Supportive Care: The Changing World of Nephrology. Journal of Advanced Nursing, 59, 644-653. https://doi.org/10.1111/j.1365-2648.2007.04383.x

[45] Pelzang, R. (2010) Time to Learn: Understanding Patient-Centred Care. British Journal of Nursing, 19, 912-917. https://doi.org/10.12968/bjon.2010.19.14.49050

[46] Stayer, D. (2012) Pediatric Palliative Care: A Conceptual Analysis for Pediatric Nursing Practice. Journal of Pediatric Nursing, 27, 350-356. https://doi.org/10.1016/j.pedn.2011.04.031

[47] Tjale, A.A. and Bruce, J. (2007) A Concept Analysis of Holistic Nursing Care in Paediatric Nursing. Curationis, 30, 45-52. https://doi.org/10.4102/curationis.v30i4.1116

[48] Kalfoss, M. and Owe, J. (2015) Empirical Verification of Swanson's Caring Processes Found in Nursing Actions: Systematic Review. Open Journal of Nursing, 5, 976-986. https://doi.org/10.4236/ojn.2015.511104

[49] Watson, J. (2002) Intentionality and Caring-Healing Consciousness: A Practice of Transpersonal Nursing. Holistic Nursing Practice, 16, 12-19. https://doi.org/10.1097/00004650-200207000-00005

[50] Coffey, S. (2006) The Nurse-Patient Relationship in Cancer Care as a Shared Covenant: A Concept Analysis. Advances in Nursing Science, 29, 308-323. https://doi.org/10.1097/00012272-200610000-00005

[51] Splaine Wiggins, M. (2008) The Partnership Care Delivery Model: An Examination of the Core Concept and the Need for a New Model of Care. Journal of Nursing Management, 16, 629-638. https://doi.org/10.1111/j.1365-2834.2008.00900.x

[52] Smith, T.D. (2001) The Concept of Nursing Presence: State of the Science. Scholarly Inquiry for Nursing Practice, 15, 299-322; Discussion 323-297.

[53] Entwistle, V., Firnigl, D., Ryan, M., Francis, J. and Kinghorn, P. (2012) Which Experiences of Health Care Delivery Matter to Service Users and Why? A Critical Interpretive Synthesis and Conceptual Map. Journal of Health Services Research and Policy, 17, 70-78. https://doi.org/10.1258/jhsrp.2011.011029

[54] Watson, J. (2008) Nursing: The Philosophy and Science of Caring. 2nd Edition, University Press of Colorado, Boulder.

[55] Efstathiou, G., Papastavrou, E., Raftopoulos, V. and Merkouris, A. (2011) Compliance of Cypriot Nurses with Standard Precautions to Avoid Exposure to Pathogens. Nursing \& Health Sciences, 13, 53-59. https://doi.org/10.1111/j.1442-2018.2011.00576.x

[56] Papastavrou, E., Efstathiou, G. and Andreou, C. (2016) Nursing Students' Perceptions of Patient Dignity. Nursing Ethics, 23, 92-103. https://doi.org/10.1177/0969733014557136

[57] Malcolm, C. (2013) Nursing Students Perceptions of Cultural Competency. Undergraduate Honors Thesis, Paper 75, East Tennesee State University, Johnson City.

[58] Malusky, S.K. (2005) A Concept Analysis of Family-Centered Care in the NICU. Neonatal Network, 24, 25-32. https://doi.org/10.1891/0730-0832.24.6.25

[59] Meghani, S.H. (2004) A Concept Analysis of Palliative Care in the United States. Journal of Advanced Nursing, 46, 152-161. https://doi.org/10.1111/j.1365-2648.2003.02975.x

[60] Mikkelsen, G. and Frederiksen, K. (2011) Family-Centred Care of Children in Hospital-A Concept Analysis. Journal of Advanced Nursing, 67, 1152-1162. https://doi.org/10.1111/j.1365-2648.2010.05574.x

[61] Meleis, A.I. (1997) Theoretical Nursing: Development and Progress. 3rd Edition, 
Lippincott, Philadelphia.

[62] Apker, J., Propp, K.M., Zabava Ford, W.S. and Hofmeister, N. (2006) Collaboration, Credibility, Compassion, and Coordination: Professional Nurse Communication Skill Sets in Health Care Team Interactions. Journal of Professional Nursing, 22, 180-189. https://doi.org/10.1016/j.profnurs.2006.03.002

[63] Watson, J. (1994) Applying the Art and Science of Human Caring. NLN, New York

[64] deQuincey, C. ( 2005) Radical Knowing: Understanding Consciousness Triology. Park St. Press, Rochester, Vancouver.

[65] Clickner, D.A. and Shirey, M.R. (2013) Professional Comportment: The Missing Element in Nursing Practice. Nursing Forum, 48, 106-113.

https://doi.org/10.1111/nuf.12014

[66] Benner, P. (2010) Educating Nurses: A Call for Radical Transformation. Vol. 3, Jossey-Bass, San Francisco.

[67] Benner, P. (1991) The Role of Experience, Narrative, and Community in Skilled Ethical Comportment. Advances in Nursing Science, 14, 1-21. https://doi.org/10.1097/00012272-199112000-00003

[68] Webb, C. and Kevern, J. (2001) Focus Groups as a Research Method: A Critique of Some Aspects of Their Use in Nursing Research. Journal of Advanced Nursing, 33, 798-805. https://doi.org/10.1046/j.1365-2648.2001.01720.x

[69] Sim, J. (1998) Collecting and Analysing Qualitative Data: Issues Raised by the Focus Group. Journal of Advanced Nursing, 28, 345-352. https://doi.org/10.1046/j.1365-2648.1998.00692.x

[70] Papastavrou, E., Efstathiou, G., Tsangari, H., Suhonen, R., Leino-Kilpi, H., Patiraki, E. and Merkouris, A. (2012) A Cross-Cultural Study of the Concept of Caring through Behaviours: Patients' and Nurses' Perspectives in Six Different EU Countries. Journal of Advanced Nursing, 68, 1026-1037. https://doi.org/10.1111/j.1365-2648.2011.05807.x

[71] von Essen, L. and Sjoden, P.O. (1993) Perceived Importance of Caring Behaviors to Swedish Psychiatric Inpatients and Staff, with Comparisons to Somatically-Ill Samples. Research in Nursing and Health, 16, 293-303. https://doi.org/10.1002/nur.4770160408

[72] von Essen, L. and Sjoden, P.O. (1995) Perceived Occurrence and Importance of Caring Behaviours among Patients and Staff in Psychiatric, Medical and Surgical Care. Journal of Advanced Nursing, 21, 266-276. https://doi.org/10.1111/j.1365-2648.1995.tb02523.x

[73] Widmark-Petersson, V., von Essen, L. and Sjoden, P.O. (2000) Perceptions of Caring among Patients with Cancer and Their Staff. Differences and Disagreements. Cancer Nursing, 23, 32-39. https://doi.org/10.1097/00002820-200002000-00005 
Submit or recommend next manuscript to SCIRP and we will provide best service for you:

Accepting pre-submission inquiries through Email, Facebook, LinkedIn, Twitter, etc. A wide selection of journals (inclusive of 9 subjects, more than 200 journals)

Providing 24-hour high-quality service

User-friendly online submission system

Fair and swift peer-review system

Efficient typesetting and proofreading procedure

Display of the result of downloads and visits, as well as the number of cited articles Maximum dissemination of your research work

Submit your manuscript at: http://papersubmission.scirp.org/

Or contact ojn@scirp.org 